Article

\title{
Measuring Online Political Dialogue: Does Polarization Trigger More Deliberation?
}

\author{
Ignacio-Jesús Serrano-Contreras * , Javier García-Marín and Óscar G. Luengo \\ Department of Political Science, University of Granada, 18071 Granada, Spain; E-Mails: nachosc@correo.ugr.es (I.-J.S.-C.), \\ javiergmarin@ugr.es (J.G.-M.), ogluengo@ugr.es (O.G.L.) \\ * Corresponding author
}

Submitted: 14 April 2020 | Accepted: 12 June 2020 | Published: 8 October 2020

\begin{abstract}
In recent years, we have witnessed an increasing consolidation of different realms where citizens can deliberate and discuss a variety of topics of general interest, including politics. The comments on news posts in online media are a good example. The first theoretical contributions called attention to the potential of those spaces to build a healthy (civic and participatory) public sphere, going much deeper in the process of political dialogue and deliberation (Fung, Gilman, \& Shkabatur, 2013; Lilleker \& Jackson, 2008; O’Reilly, 2005; Stromer-Galley \& Wichowski, 2011). Polarization has been configured as a constant feature of the quality of the mentioned dialogues, particularly in Mediterranean countries (polarized pluralists' cases). One of the research challenges at the moment has to do with the scrutiny of polarization within the political deliberation provoked by news stories. The goal of this article is the analysis of political dialogue from the perspective of the polarization in the increasingly popular network YouTube, which is presenting very particular characteristics. Using a sample of almost 400,000 posted comments about diverse topics (climate change, the Catalonian crisis, and Political parties' electoral ads) we propose an automated method in order to measure polarization. Our hypothesis is that the number of comments (quantitative variable) is positively related to their polarization (qualitative variable). We will also include in the examination information about the ideological editorial line of newspapers, the type of topic under discussion, the amount of traceable dialogue, etc. We propose an index to (1) measure the polarization of each comment and use it to show how this value has behaved over time; and (2) verify the hypothesis using the average polarization of comments for each video.
\end{abstract}

\section{Keywords}

algorithms; polarization; public sphere; social media; text mining; YouTube

\section{Issue}

This article is part of the issue "The Ongoing Transformation of the Digital Public Sphere" edited by Emiliana De Blasio (LUISS University, Italy), Marianne Kneuer (Hildesheim University, Germany), Wolf J. Schünemann (Hildesheim University, Germany) and Michele Sorice (LUISS University, Italy).

(C) 2020 by the authors; licensee Cogitatio (Lisbon, Portugal). This article is licensed under a Creative Commons Attribution 4.0 International License (CC BY).

\section{Introduction}

Political interaction is essential for democratic societies. Through dialogue, citizens clarify their points of view, come into contact with the opinions of other parties, and shape the problems that people need to face (Stromer-Galley \& Wichowski, 2011). Some scholars have pointed out that conversations about topics of general interest are a requirement for the integral understanding of democratic life and, consequently, are fundamental in order to provide the meaning of effective political participation, reinforcing the legitimacy of democratic systems (Rubio, 2000; Scheufele, 2001).

In the last decade, we have witnessed the proliferation of different online spaces for discussion, information exchange and deliberation that were pointed out as potential spheres for political dialogue. Around the end of the first decade of the 21st Century, when social 
media-understood as applications and websites employed to share information and build networks between people (Osborne-Gowey, 2014)-started to gain attention in detriment of other traditional 1.0 online platforms (online newspaper blogs), journalists, analysts, and scholars began to speculate about the real possibility to generate domains where regular citizens could find a space to share information, to portray social and political events, to exchange opinions, and to dialogue, far away (at least in theory) from the biased editorial alignment of international news corporations. Those platforms create a networked sphere of political discussions that is structurally independent from the traditional arena of politics or news; yet, it connects with the two through official affiliations and real-life interactions (Lindgren, 2011). Hence, we have observed the transformation of the public sphere, from a traditional model based on a strongly hierarchical and mainly one-way mass communication, to a network-based multidirectional and horizontal communication (López García, 2006).

Most of the communication research attention on political deliberation in the last years has been focused on the interactions observed in Twitter and Facebook (Conover et al., 2011; Grusell \& Nord, 2012; Gruzd \& Roy, 2014; Jaidka, Zhou, \& Lelkes, 2019; Marichal, 2016; Oz, Zheng, \& Chen, 2018). We assume that behind this fact is not only the traditional leadership of those social networks, but also the relatively easier logistic process of extracting and generating samples for analysis. These studies are focused on platforms that were designed to link people together. YouTube, instead, was built as a video $\log$, although its functions are shifting to a more social media like logic. The inclusion of a recommendation system, likes and dislikes, combined with the management of data, enable us to consider YouTube as an online social network (Ma, Wang, Li, Liu, \& Jiang, 2013). Thus, it is considered more than just a place to watch and share videos, since it is also used as a learning tool (Allgaier, 2019).

The goal of this article is the analysis of political dialogue from the perspective of the polarization in YouTube, which presents very particular characteristics. Launched in 2005, YouTube is the biggest online video platform worldwide, featuring a wide variety of usergenerated and corporate media content, and the second largest social network, in terms of monthly active users, after Facebook. YouTube has more than 1,900 million users that logged in every month, generating more than 1,000 million hours of content, with local versions in 91 countries. Our final purpose is to check what kind of polarization patterns might be observed from comments on YouTube. To this end, we will analyze the comments regarding the most popular videos on three topics: Election commercials, climate change and the Catalonian political conflict; each of which observed in the context of Spain. The final ambition of this proposal is to make methodological progress in the understanding of online political dialogue by the measuring of polarization with an innovative quantitative tool.

\section{Political Deliberation}

Citizens in democracies, particularly in the Western world and as a consequence of technological developments, are in the best position to participate in public discussions. New environments have displayed an impressive potential to improve democracy, creating more inclusive, receptive, deliberative and participatory political systems, in other words, contributing to the consolidation of an effective public sphere. This central concept has been defined by contemporary political theorists as a communicative space in which matters of common prominence are considered for discussion by those concerned and affected, in a way that fulfils a number of ambitious normative criteria (Dahlberg, 2004). Statements should consist of arguments, supported by an appropriate reasoning whose validity can then be checked by others. The process requires understanding from other participants, and a true and honest effort to come to a shared conclusion. All interested parties should be allowed to participate. Finally, the best arguments should prevail (Schäfer, 2016).

Ferree, Gamson, Gerhards, and Rucht (2002) proposed different models of public sphere in today's democracies. They distinguished four types of traditions where this concept finds arrangement, and specified the criteria that each perspective endorses and emphasises regarding who participates, in what sort of processes, how ideas should be presented, and the outcome of the relation between discourse and decision-making. Consequently, we can point out different combinations of criteria based on four theory types: Representative Liberal, Participatory Liberal, Discursive, and Constructionist (Ferree et al., 2002, p. 316).

Social networks show great potential for achieving greater political inclusion and participation, for example, giving visibility to voices marginalized by the mainstream (Berry, Kim, \& Spigel, 2010; Bimber, 1998). Social networks also enable engaged citizens to approach other interlocutors to share information, contrast opinions or forge a position regarding a major public event. Therefore, networks have a very high potential to provide the perfect environment to foster dialogue around important policy issues. Unlike other traditional media, social media have facilitated a connection between people, regardless of distance, geographical location or political affiliation. The advent of online media has been considered as a second structural transformation of the public sphere.

Many scholars in the last years have contributed to the discussion on the updated notion of digital public sphere. This new notion includes some renewed important aspects. Following Schäfer, we approach the concept of communicative sphere from a broad perspective, including social media, websites, social network sites, weblogs, and micro-blogs; in all cases, sites where participation is open and freely available to everybody who is interested, where matters of common concern can 
be discussed, and where proceedings are visible to all (Schäfer, 2016).

However, the literature shows little agreement on the true scope of the political transformations by social media. Beyond some commonalities, the existing schools of digital public sphere theory differ in what kinds of communication they consider desirable. For almost three decades, different academic contributions (mainly theoretical) have asserted strong hopes and fears regarding the development of an online public sphere and its effects on society. Therefore, there are great doubts about the articulation of an effective, more inclusive and deliberative public sphere which is self-mediated (Chadwick, 2009; Hindman, 2009). We can say that social networks may not be definitive when generating a unified public sphere. Similarly, it is difficult to calibrate how the new social media will consolidate two-way communication channels with institutions, parties and candidates. On the one hand, no one seems to question that online media provide a relatively open, easy, and fast access to information, enable more people to make their voices heard in society, and help to produce new kinds of communication. On the other hand, we can point out other factors stated by some pessimistic scholars: Firstly, equal access to online sources of participation is a fiction, thanks to multiple digital divides. Secondly, the danger of fragmentation into small communities of like-minded people veers from a real exchange between participants (e.g., filter bubbles). Thirdly, the inevitable pressure of economic influences on a biased selection of topics to be discussed. And, lastly, the lack of social courtesy derived from an absent face-to-face communication leads to an irrational, emotional and somehow unrespectful interaction (Schäfer, 2016). In that sense, many skeptics understand that a high level of anonymity can exacerbate uninhibited communicative behaviors, moving in the direction of increased disrespectful and even aggressive political discussion (Rowe, 2014). In this sense, we can observe examples of polarization, radicalization or activism in the so-called trolls. This is what Byung-Chul Han calls 'swarm democracy' (Han, 2014), which could be defined as the private sum of reactive multitudes, which move on the basis of discharges of flattery or disqualification and which, like an earthquake, shake up the spaces provided by social networks. Rather than promoting rational and informed deliberation, social media work by amplifying and modulating an atmosphere of individual and collective feelings and actions (Arias Maldonado, 2016). Thus, the interaction between personal networks is altered, with small-scale movements that, together, will produce enormous effects (Granovetter, 1973). The zero threshold would be filled with individuals who are ready for action and prepared for conflict (Petersen, 2020).

In addition, in recent times we have been able to see how the dissemination of biased and malicious information (fake news), primarily aimed at altering perceptions of political discourses, distributing misinformation or directly manipulating, has influenced the dynamics of on- line political conversations, and even political outcomes. A recent report from the Pew Research Center estimates that two-thirds of the links tweeted on the most popular pages belong to automatic, non-human accounts (Wojcik, Messing, Smith, Rainie, \& Hitlin, 2018).

Currently, polarization has been included as one of the main social and political phenomena of the present century, being a traditional object of study within political communication (see, for example, the excellent study by Sunstein, 2002), especially from the media (Prior, 2013) or political perspectives (Gentzkow, Shapiro, \& Taddy, 2016). In that way, the work by Hallin and Mancini (2004) proposed a definition of polarization as partisan coverage by the media and has even constituted the basis of their different models of political and media systems. However, polarization has also been defined as a media or even a political effect (Bernhardt, Krasa, \& Polborn, 2008). In addition, we can find other perspectives where this process can be considered as the distance between opposing political views. Some traditional studies in the case of the United States in the last decades are good examples: those focused on the increasing divergences between Democrats and Republicans (Mason, 2014). Those studies on polarization have increased in recent years, especially in the wake of the current political situation in the United States, where there seems to be a feeling of growing dislike and distrust between the supporters of both parties. In fact, the term 'affective polarization' is used to describe it (lyengar, Lelkes, Levendusky, Malhotra, \& Westwood, 2019). These contexts offer new meanings and measures that state a potential direction of this development. The case of Spain is not an exception: The political boundaries represented in the national parliament have become sharper in recent years, and two very different and antagonist blocs actively emerged. The phenomenon generated new parties within political wings (Bramson et al., 2017). This portrayal is also replicated at the regional level with another kind of polarization with particular variables and settings. In this sense, we are addressing different and complex involvements developed over time, across populations and comparatives studies (Bramson et al., 2017). Thus, assumptions about the notion of polarization continue open. Its main meaning is related to the growth of the space between poles, caused, mostly, by the influence of emotions and beliefs, above evidence and reason (Goldman \& O'Connor, 2019; Mason, 2014; Olsson, 2013). Such distinctions could drive to extreme positions (Fletcher \& Jenkins, 2019; Gidron, Adams, \& Horne, 2019).

Naturally, with the evolution of the mass media paradigm, new ideas are emerging that reflect the scope of change. One such change (Bessi et al., 2016) is the emergence of non-mediated processes, at least by journalists (Prior, 2013). Another is that the new public sphere is fundamentally virtual. Recently, scholars have found multiple evidence that social media and the general Internet environment can cause an increase in po- 
litical or ideological polarization (Tucker et al., 2018). Particularly, research on online deliberation has identified a series of problems with online debate: Groups are often composed of like-minded people, so issues that generate disagreement or difficulty tend to be avoided. At the same time, a spiral of analogous reasoning occurs where deliberation does not exist (Wright, Graham, \& Jackson, 2017). To reflect that, some authors coined the concept of 'echo chambers' (Bail et al., 2018). Those chambers have the effect of isolating individuals from opposing points of view, spinning the polarizing effects. But there are authors who claim that these effects can come from selective exposure, for example on Facebook (Spohr, 2017). However, almost all these studies focus on the consumption of information on Facebook or Twitter (Conover et al., 2011), defined even as junk news (Narayanan et al., 2018).

Continuing in this vein, social network products must be approached from new perspectives due to new semantic styles and the large amount of data available. Our aim is to understand how deliberation occurs and whether it could be derived from an apparent polarization (Bramson et al., 2017).

\section{Design}

Our basic assumption is that an increase in political deliberation should trigger more polarization. Hence:

$\mathrm{H} 1$ : There is a direct relation between polarization and deliberation.

Given the volume of literature on social media polarization, the lack of operational definitions is surprising. Scholars often assume that polarization is a result of differing views on ideological or political issues, but offer few clues on how to measure this dynamic. From this perspective, we can define polarization as "the existence of two or more alternative and relatively coherent visions that contradict their most important elements. Polarized coverage tends to strongly criticize the opposing view, making the public more reluctant to consider the opposing position legitimate" (Balán, 2013, p. 477).

But the problem still persists: How do we measure polarization? We propose to use Balan's definition centered in the existence of criticism to try to create a consistent way to measure this concept. Polarization, then, implies that people "hold overwhelmingly positive views of their own co-partisans and highly negative views of those on the other side of the political spectrum" (Gentzkow, 2016, p. 13). Therefore, we can affirm that the wider the distance between positive and negative statements, the greater polarization of the topic (or text). In fact, polarization itself can be the aforementioned distance.

Nowadays, there are different tools for measuring positive and negative texts, fundamentally sentiment analysis. This type of analysis, used routinely by both industry and academia, is the basis of many tools and computer algorithms. Sentiment analysis-and opinion mining-is the field of study that analyzes people's opinions, sentiments, evaluations, attitudes, and emotions in written language. It is one of the most active research areas in natural language processing and is also widely studied in data mining, Web mining, and text mining (Liu, 2012). Although sentiment analysis can use different techniques, there are usually two approaches: The use of a supervised learning algorithm trained with human coded data; or the use of a lexicon (a dictionary) to infer the tone of the text through an automated analysis (based on the presence of a specific keyword, a group of them, or a bag of words). The first approach works well when dealing within specific topics (García-Marín \& Calatrava, 2018) and the second is more transversal but may offer less accuracy if the lexicon is not adequately created (Boukes, van de Velde, Araujo, \& Vliegenthart, 2019). Although sentiment analysis has been justly criticized, it does offer some useful information to researchers, as long as it is based on wellweighted dictionaries (Boukes et al., 2019).

There are not many sentiment lexicons for languages other than English, but the number is growing. However, many of them are just automatic translations using different resources, such as Google Translator, which can lead to important mismatches. In the case of the Spanish language, there are several dictionaries designed specifically for sentiment analysis. In this research we are going to use ML-SentiCon. We consider it an ideal resource: It has been evaluated (something not too common) and corrected (at least in 4 of 8 layers), and consequently is not a mere translation. It has 8 layers, depending on reliability, from more to less reliable. The first layer has 97.73\% and the last $61.29 \%$ : We have decided to use 6 layers, accumulating 2848 words with a reliability of $86.09 \%$. The results are significantly lower than those obtained for the English language but we understand that they are enough for the measurement of polarization in the Spanish language (Cruz, Troyano, Pontes, \& Ortega, 2014). Since sentiment analysis is not an accurate measure of polarization, in this article we propose a way to measure polarization from our corpus. We propose the development of an index to quantify this phenomenon, through the weighting of values with which to operate (Ferrando, 1987, p. 34). To that end we have operationalized the polarization of a comment $(P C)$ from the distance between the sentiment analysis of the comments $(S)$ and the median of the sentiment analysis aggregate of all the comments of each processed video $(\mathrm{Me})$, in absolute number. In this way we obtain a number that can take any value between 0 and 2 , where 0 is no polarization and 2 is the maximum polarization:

$$
P c=|(S-M e)|, \text { where } S \in[-1,1], p \in(0,2)
$$

Then, the median of the polarization measure has been calculated again to give each video an average polarization $(P y=M e \vee(S-M e S) \vee p y=M e(p c))$ that was useful to relate this dimension $e$ to the rest of the vari- 
ables of each video. Therefore, the results of applying the formula are as follows: a measure of the polarization of each comment, used to show how polarization has behaved over time; and, second, a measure of the average comment's polarization of each video, used to observe the specific connections in order to demonstrate our hypothesis.

The database is composed of YouTube video interactions. We decided to use YouTube because it stands out from other social media in that the video is the primary piece, leaving the text on a secondary level. However, the interactions that open up within it are multiple. In this way, we will have the possibility of analyzing very broad patterns of behavior (number of views, likes or dislikes, replies,...), as well as the potential relationships between them.

Data extraction took place on October 25, 2019. The collection was based on three topics and two search patterns, producing a total of 600 videos, disaggregated as shown in Table 1 . The first pattern was the use of the following keywords in the YouTube search engine: "cambio climático" (climate change) and "independencia de cataluña" (independence of Catalonia), from which the 200 most viewed videos per topic were selected. The second search pattern was selected from the YouTube channels of the five Spanish parties with the most parliamentary representation after the April 2019 elections: PSOE, PP, Ciudadanos, Podemos, and Vox. The 40 most viewed pieces posted by political groups within their respective channels were selected, resulting in a total of 200 videos. Out of the total 600 videos, 19 of them had the comment board disabled: 12 of these were from political parties, 4 on "independencia de cataluña" and 3 on "cambio climático."

The final result of the search, and subsequent cleansing, produced a total corpus of 391,591 comments divided into:

- "Catalonian independence": 162,789

- "Climate change" (as a hoax or scientific fact): 124,820

- Political parties' videos (their official channels): 103,982

Of course, we decided to use these three topics because we understand that they are susceptible to producing polarizing behavior.

\section{Results}

We believe that the proposed measure of polarization has a great explanatory potential (Figure 1). In the three cases analyzed, the images show important details that, to a great extent, portray the actual informative dynamic. In the case of Catalonia (at the top in Figure 1), there are two clear points: September-December 2017 and September-October 2019. Both are the moments of greatest tension in the political conflict: The first represents the failed declaration of independence and, the second, the Supreme Court's decisions on some proindependence Catalonian politicians (with minor peaks that coincide with elections in Catalonia in recent years). The second case, on climate change, is less evident, since there are no important events in this regard, although there is a clear increase in polarization during the analyzed years. And finally, in the case of political parties, there are also some peaks that mainly correspond to electoral periods in Spain. That is, we think that, in fact, measuring polarization as the difference between positive and negative feelings has great explanatory potential.

As mentioned before, we consider the three topics as potentially polarizing. Although the proposed index shows great explanatory potential, Table 2 indicates that the hypothesis is negative. That is, the relationship between the number of comments and their polarization is not positive in all cases. Specifically, there is a positive, although weak, relationship for the cases of climate change and political parties, but not for the Catalonian political conflict.

Of course, the same behavior is reproduced with the rest of the variables: The number of visits, comments, likes or dislikes present the same results. This is not really surprising, since they are numerical variables that tend to increase as a whole (i.e., the more visits, the more likes, dislikes, and comments). We understand, then, that contextual differences, specific to each topic, affect the results.

At the moment, it seems difficult to understand how the deliberations in social media could become polarized. There may indeed be underlying factors that favor it, such as confirmation bias and content promotion algorithms. Both situations could encourage the construction of echo chambers (Bessi et al., 2016). However, in our study we have observed that there are aspects that differ. In the case of videos on climate change and those of

Table 1. Analyzed videos and comments from YouTube.

\begin{tabular}{lcccrrrrr}
\hline & & & & & & Views for \\
& Videos & Views & Comments & Likes & Dislikes & comment & Med_Pol & SD \\
\hline Catalonian independence & 192 & 37.765 .741 & 163.545 & 430.074 & 151.717 & 230 & 0.23 & 0.07 \\
Climate change & 186 & 68.460 .219 & 104.175 & 1.019 .987 & 67.450 & 657 & 0.19 & 0.10 \\
Political parties' & 159 & 44.239 .860 & 124.019 & 672.596 & 123.015 & 357 & 0.20 & 0.08 \\
Total & 537 & 150.465 .820 & 391.739 & 2.122 .657 & 342.182 & & 0.20 & 0.08 \\
\hline
\end{tabular}



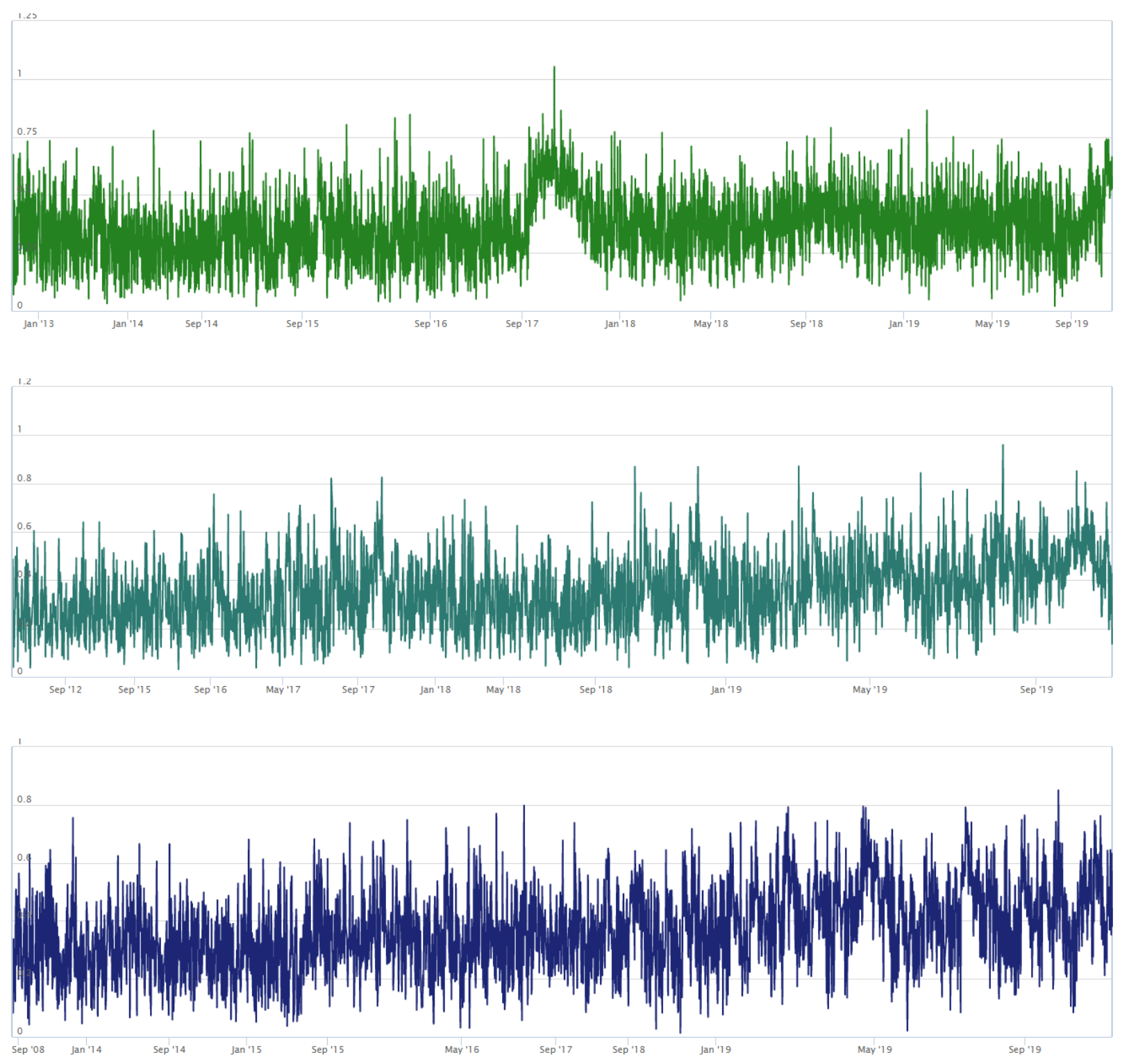

Figure 1. Polarization through time: Catalonian independence, climate change and political parties (from top to bottom).

political parties, the presence of this polarization could be influenced by the presence of active trolls that radicalize the conversation. Nonetheless, there could also be external factors that we have not controlled. However, the conflict in Catalonia behaves differently. Although the index does seem to be illustrative, the correlations reject the model based on the fact that greater participation produces greater polarization. However, the behavior of deliberation in the Catalonian conflict is similar to the other issues on very specific dates, such as September and October 2017 (see Figure 1). In that year, 2017, different events took place, such as the so-

Table 2. Spearman correlations (polarization) $\left(R_{s}\right)$.

\begin{tabular}{|c|c|c|c|c|}
\hline & $\begin{array}{c}\text { All } \\
(n=537)\end{array}$ & $\begin{array}{l}\text { Climate change } \\
\quad(n=186)\end{array}$ & $\begin{array}{l}\text { Catalonian independence } \\
\qquad(n=192)\end{array}$ & $\begin{array}{l}\text { Political parties } \\
\qquad(n=159)\end{array}$ \\
\hline Publish_date & $0.161^{* *}$ & $0.265^{* *}$ & 0.090 & 0.043 \\
\hline ViewCount & 0.048 & $0.215^{* *}$ & -0.027 & 0.151 \\
\hline Comments & $0.269 * *$ & $0.311^{* *}$ & -0.005 & $0.400 * *$ \\
\hline Likes & $0.100 *$ & $0.228^{* *}$ & -0.076 & $0.220^{* *}$ \\
\hline Dislikes & $0.144^{* *}$ & $0.248 * *$ & -0.015 & $0.236 * *$ \\
\hline
\end{tabular}

Notes: ${ }^{*}$ significant at $\mathrm{p}<0.01 ;{ }^{* *}$ significant at $\mathrm{p}<0.001$. 
called Disconnection Law or the October 1st referendum (in both cases serious and polemic attacks against the Spanish constitution). These two events attracted a great deal of media attention and, accordingly, also the interest of YouTube users. This trend seems to be manifesting itself again in the following major media event, which took place in October 2019 (ruling of the Spanish Supreme Court on the events of 2017). Undoubtedly, there are temporal trends that, unlike previous periodssuch as 2014-, are more likely to relate greater participation to greater polarization, as occurred in the other two issues. These discrepancies open the door to new ideas that should be investigated, to explain how in certain scenarios polarization is not instigated by participation.

So, how do we interpret the Catalonian case? The first thing we can say is that, surprisingly, the Catalonian case is characterized by less polarization (except for some very specific dates). This fact, on the other hand, may be consistent with some findings by the academic community. Firstly, perhaps the most obvious factor is the traditional media attention. When this is greater, the behavior of polarization seems to resemble that of other issues. However, when there is not such a presence, the open discussions linked to these videos are not affected by constant polarization, leaving the polarization index without very high values (which does not mean, in any case, that it is positive or negative). Secondly, this argument can accommodate (not replace) a moderate influence driven by filter bubbles. That is, a separation in media consumption could occur according to ideological position. That consumption would be moderated, surely, by activism (the more activism, the more consumption of related information). And the effect would be similar: a low polarization, since the ideological point of view of the participants is similar.

At present, these effects act as echo chambers and filter bubbles. This conception has been intense, especially since 2009, when Google began to modify its search engine to suit the user (Pariser, 2011). While filter bubbles are generated from an unconscious action of the user, echo chambers must prevail consciously, hence one may be part of the other. The assumption that differentiates the two is the willingness and predisposition for users to manifest in the creation of an environment (Klapper, 1960; Knobloch-Westerwick, 2015; Rubin, 2002) governed by scales of reliability: constituents (unaided), major fundraisers, local media, colleagues, national media, advertising \& lobbyists (Scruggs, 1998). In order to construct the bubble within the network, and to generate the alteration of behavior, it is necessary to develop both analogical and digital reflections (Holbert \& Stephenson, 2003).

In the case of the other two topics, a partisan (ideological) predisposition towards the topic under discussion is especially palpable in the videos of political parties where the predisposition towards certain channels is influenced by external factors (Barberá, Jost, Nagler, Tucker, \& Bonneau, 2015). This would make focus on cer- tain YouTube channels (not on specific videos) interesting, such as those of political parties.

If that is true, the data would show that YouTube content is permeable to the traditional media agenda (which, in turn, can be an indicator of the popularity of an issue, not its origin). In other words, there are moderators to be controlled. This dynamic could cause the debate to shift and polarize in YouTube (due to the possibilities that the platform offers). In other words, events of great media interest (the dates mentioned of 2017 and 2019 for the Catalonian case or the specific dates of the political parties' election campaigns), are more favorable to a positive correlation between participation and polarization.

\section{Conclusion}

The first conclusion is that the main hypothesis has not been fully verified. There are no significant relationships suggesting that increased participation leads to increased polarization, at least at the aggregate level. There are indications that such a relationship may exist at specific time periods or for specific issues. This shows (especially in the Catalonian issue) that there are intervening variables (the context, the issue, the time frame, etc.) that have not been controlled. These variables are not playing comparable roles in the three topics under examination. This could help to explain disparities in the significance. Despite this, new computer techniques do prove useful for a better understanding of these phenomena, especially when working with large data sets. Thus, we believe that this study sheds light on YouTubers' behavior, which is part of our purpose. However, it is necessary to develop different tools to understand the functioning of polarization in social networks. The methodology presented has proven to be reliable during the analysis in measuring the polarization of YouTube comments. According to its conception, it could be used on different samples of very different nature. In turn, YouTube has shown to be a network without as many limits as Facebook or Twitter, and less opaque.

As Sunstein (2008) points out, to the extent that there are different social media networks, and within them an almost infinite variety of compartments, regular users end up choosing their interlocutors and the most comfortable space for them. In this sense, it is argued that networks constitute 'echo chambers' in which we only hear the echo of our own predispositions. Consequently, in such spaces contact between groups with different opinions could be more difficult and reinforcement mechanisms could become the main effects. Moreover, the fragmentation of public opinion can have a reducing effect on social cohesion.

Thus, we could expect a deeper radicalization of the opinions of Internet users who never confront their potential opponents online. Therefore, a mechanism similar to that announced by Lazarsfeld, Berelson, and Gaudet in the 1940s (1960) could emerge, based on selective perceptions, which would be reactivated in a 
somewhat different way. These mechanisms would point in a similar direction by reinforcing rather than challenging or opposing previous inclinations towards public issues.

As we insisted before, there is a tension between an 'optimistic' approach, which argues that social networks enable interaction between different citizens and thus foster pluralistic debates, and a critical approach, which argues that networks facilitate segregation across ideological lines and then reduce debates by avoiding the contact of contradictory opinions. Discussions about the potential and actual role of social media in public debate are often foreshortened to a mere contest between utopian and dystopian perspectives (Bruns, 2018): It is the balance between utopian and dystopian visions that unveils the true nature of the Internet as a public sphere (Papacharissi, 2002). Although, in order to conclude, we can affirm that the social media, undoubtedly, show a great capacity to respond to citizens' needs. This fact becomes much more important in the current context of disaffection and political unpredictability. The possibilities of social networks are enormous. In political terms, we can recognize beneficial effects: (a) they help to make political discourse more pluralistic; (b) they facilitate greater public involvement and allow citizens to monitor and control power and participate in decisionmaking; (c) they produce and offer more information; and (d) they provide new formats for the transmission of political content. Even so, the revolution presented by the media is complex and on countless levels. We are talking about systems that are growing all the time, changing the process and the function. This kind of evolution can be seen in the constant dynamism used in the algorithms they employ. In this way, we could find enormous improvements in the development of computing applied to the web. In that sense, we can underline the adjustment implemented by Google in its browser and platformsYouTube is a good example of it (Covington, Adams, \& Sargin, 2016), going from simple machine learning to elaborate neural networks. We assume that the contribution from academia will be to enhance models and techniques of research in order to prevent, insofar as possible, adverse potential effects.

\section{Acknowledgments}

The authors wish to thank the Editors for their excellent work and the anonymous reviewers for their valuable feedback and suggestions.

\section{Conflict of Interests}

The authors declare no conflict of interests.

\section{References}

Allgaier, J. (2019). Science and environmental communication on YouTube: Strategically distorted commu- nications in online videos on climate change and climate engineering. Frontiers in Communication, 4. https://doi.org/10.3389/fcomm.2019.00036

Arias Maldonado, M. (2016). La digitalización de la conversación pública: Redes sociales, afectividad política y democracia [The digitalization of public conversation: Social media, political affectivity and democracy]. Revista de Estudios Políticos, 173, 27-54.

Bail, C. A., Argyle, L. P., Brown, T. W., Bumpus, J. P., Chen, H., Hunzaker, M. F., . . . Volfovsky, A. (2018). Exposure to opposing views on social media can increase political polarization. Proceedings of the $\mathrm{Na}$ tional Academy of Sciences, 115(37), 9216-9221.

Balán, M. (2013). Polarización y medios a 30 años de democracia. Revista SAAP: Sociedad Argentina de Análisis Político, 7(2), 473-481.

Barberá, P., Jost, J. T., Nagler, J., Tucker, J. A., \& Bonneau, R. (2015). Tweeting from left to right: Is online political communication more than an echo chamber? Psychological Science, 26(10), 1531-154.

Bernhardt, D., Krasa, S., \& Polborn, M. (2008). Political polarization and the electoral effects of media bias. Journal of Public Economics, 92(5/6), 1092-1104.

Berry, C., Kim, S., \& L. Spigel (2010). Electronic elsewheres: Media technology and the experience of social space. Minneapolis, MN: University of Minnesota Press.

Bessi, A., Zollo, F., Del Vicario, M., Puliga, M., Scala, A., Caldarelli, G., ... Quattrociocchi, W. (2016). Users polarization on Facebook and Youtube. PLOSONE, 11(8). https://doi.org/10.1371/journal.pone.0159641

Bimber, B. (1998). The Internet and political transformation: Populism, community, and accelerated pluralism. Polity, 31(1), 133-160.

Boukes, M., van de Velde, B., Araujo, T., \& Vliegenthart, R. (2019). What's the tone? Easy doesn't do it: Analyzing performance and agreement between off-theshelf sentiment analysis tools. Communication Methods and Measures, 14(2), 83-104.

Bramson, A., Grim, P., Singer, D. J., Berger, W. J., Sack, G., Fisher, S., ... Holman, B. (2017). Understanding polarization: Meanings, measures, and model evaluation. Philosophy of Science, 84(1), 115-159.

Bruns, A. (2018). Gatewatching and news curation: Journalism, social media, and the public sphere. New York, NY: Peter Lang.

Chadwick, A. (2009). Web 2.0: New challenges for the study of e-democracy in an era of informational exuberance. I/S: A Journal of Law and Policy for the Information Society, 5(1), 9-41.

Conover, M. D., Ratkiewicz, J., Francisco, M., Gonçalves, B., Menczer, F., \& Flammini, A. (2011). Political polarization on Twitter. In Proceedings of the Fifth International AAAI Conference on Weblogs and Social Media (pp. 89-96). Palo Alto, CA: AAAI.

Covington, P., Adams, J., \& Sargin, E. (2016). Deep neural networks for YouTube recommendations. In RecSys '16: Proceedings of the 10th ACM Conference on 
Recommender Systems (pp. 191-198). New York, NY: Association for Computing Machinery.

Cruz, F. L., Troyano, J. A., Pontes, B., \& Ortega, F. J. (2014). Building layered, multilingual sentiment lexicons at synset and lemma levels. Expert Systems with Applications, 41(13), 5984-5994.

Dahlberg, L. (2004). The Habermasian public sphere: A specification of the idealized conditions of democratic communication. Studies in Social and Political Thought, 10, 2-18.

Ferrando, M. G. (1987). Socioestadística: Introducción a la estadística en sociología [Socio-statistics: Introduction to statistics in sociology]. Madrid: Alianza Universidad Textos.

Ferree, M. M., Gamson, W. G., Gerhards, J., \& Rucht, D. (2002). Four models of the public sphere in modern democracies. Theory and Society, 31(3), 289-324.

Fletcher, R., \& Jenkins, J. (2019). Polarisation and the news media in Europe. Brussels: European Parliamentary Research Service.

Fung, A., Gilman, H. R., \& Shkabatur, J. (2013). Six models for the Internet \& politics. International Studies Review, 15, 30-47.

García-Marín, J., \& Calatrava, A. (2018). The use of supervised learning algorithms in political communication and media studies: Locating frames in the press. Comunicación y Sociedad, 31(3), 175-188.

Gentzkow, M. (2016). Polarization in 2016. Toulouse: Toulouse Network for Information Technology.

Gentzkow, M., Shapiro, J., \& Taddy, M. (2016). Measuring polarization in high-dimensional data: Method and application to congressional speech (SIEPR Discussion Paper No. 16-028). Stanford, CA: SIEPR.

Gidron, N., Adams, J., \& Horne, W. (2019). How ideology, economics and institutions shape affective polarization in democratic polities. Presented at the Annual Conference of the American Political Science Association.

Goldman, A., \& O'Connor, C. (2019). Social epistemology. In E. Zalta (Ed.), Stanford encyclopedia of philosophy. Retrieved from https://plato.stanford.edu/ entries/epistemology-social

Granovetter, M. (1973). The strength of weak ties. American Journal of Sociology, 78(6), 1360-1380.

Grusell, M., \& Nord, L. (2012). Three attitudes to 140 characters: The use and views of Twitter in political party communications in Sweden. Public Communication Review, 2(2), 48-61.

Gruzd, A., \& Roy, J. (2014). Investigating political polarization on Twitter: A Canadian perspective. Policy \& Internet, 6, 28-45.

Hallin, D. C., \& Mancini, P. (2004). Comparing media systems: Three models of media and politics. Cambridge: Cambridge University Press.

Han, B. C. (2014). En el enjambre [In the swarm]. Barcelona: Herder Editorial.

Hindman, M. (2009). The myth of digital democracy. Princeton, NJ: Princeton University Press.
Holbert, R. L., \& Stephenson, M. T. (2003). The importance of indirect effects in media effects research: Testing for mediation in structural equation modeling. Journal of Broadcasting \& Electronic Media, 47(4), 556-572.

Iyengar, S., Lelkes, Y., Levendusky, M., Malhotra, N., \& Westwood, S. J. (2019). The origins and consequences of affective polarization in the United States. Annual Review of Political Science, 22, 129-146.

Jaidka, K., Zhou, A., \& Lelkes, Y. (2019). Brevity is the soul of Twitter: The constraint affordance and political discussion. Journal of Communication, 69(4), 345-372.

Klapper, J. T. (1960). The effects of mass communication. Glencoe, IL: Free Press.

Knobloch-Westerwick, S. (2015). Choice and preference in media use. New York, NY: Routledge.

Lazarsfeld, P., Berelson, B., \& Gaudet, H. (1960). The people's choice. New York, NY: Columbia University Press.

Lilleker, D. G., \& Jackson, N. (2008). Politicians and Web 2.0: The current bandwagon or changing the mindset? Paper presented at the Politics: Web 2.0 International Conference, London, UK.

Lindgren, S. (2011). YouTube gunmen? Mapping participatory media discourse on school shooting videos. Media, Culture \& Society, 33(1), 123-136.

Liu, B. (2012). Sentiment analysis and opinion mining. Synthesis lectures on human language technologies, 5(1), 1-167.

López García, G. (2006). Comunicación en red y mutaciones de la esfera pública [Online communication and changes in the public sphere]. Zer, 20, 231-249.

Ma, X., Wang, H., Li, H., Liu, J., \& Jiang, H. (2013). Exploring sharing patterns for video recommendation on YouTube-like social media. Multimedia Systems, 20(6), 675-691.

Marichal, J. (2016). Facebook democracy: The architecture of disclosure and the threat to public life. New York, NY: Routledge.

Mason, L. (2014). "I disrespectfully agree": The differential effects of partisan sorting on social and issue polarization. American Journal of Political Science, 59(1), 128-145.

Narayanan, V., Barash, V., Kelly, J., Kollanyi, B., Neudert, L. M., \& Howard, P. N. (2018). Polarization, partisanship and junk news consumption over social media in the US. arXiv. https://arxiv.org/abs/1803.01845

Olsson, E. J. (2013). A Bayesian simulation model of group deliberation and polarization. In F. Zenker (Ed.), Bayesian argumentation: The practical side of probability (pp. 113-133). Dordrecht: Springer.

O'Reilly, T. (2005). What Is Web 2.0: Design patterns and business models for the next generation of software. O'Reilly. Retrieved from https://www.oreilly. $\mathrm{com} /$ pub/a/web2/archive/what-is-web-20.html? page $=$ all

Osborne-Gowey, J. (2014). What is social media. Fisheries, 39(2), 55-55. 
Oz, M., Zheng, P., \& Chen, G. M. (2018). Twitter versus Facebook: Comparing incivility, impoliteness, and deliberative attributes. New Media \& Society, 20(9), 3400-3419.

Papacharissi, Z. (2002). The virtual sphere: The internet as a public sphere. New Media \& Society, 4(1), 9-27.

Pariser, E. (2011). The filter bubble: What the Internet is hiding from you. New York, NY: Penguin Press

Petersen, M. B. (2020). The evolutionary psychology of mass mobilization: How disinformation and demagogues coordinate rather than manipulate. Current Opinion in Psychology, 35, 71-75.

Prior, M. (2013). Media and political polarization. Annual Review of Political Science, 16, 101-127.

Rowe, I. (2014). Civility 2.0: A comparative analysis of incivility in online political discussion. Information, Communication \& Society, 18(2), 121-138.

Rubin, A. M. (2002). The uses-and-gratifications perspective of media effects. In J. Bryant \& D. Zillmann (Eds.), Media effects: Advances in theory and research (pp. 525-548). New York, NY: Routledge.

Rubio, R. (2000). Internet en la participación política [Internet in political participation]. Revista de Estudios Políticos, 109, 285-302.

Schäfer, M. S. (2016). Digital public sphere. In G. Mazzoleni (Ed.), The international encyclopedia of political communication. https://doi.org/10.1002/ 9781118541555.wbiepc087. Retrieved from https:// onlinelibrary.wiley.com/doi/book/10.1002/ 9781118541555

Scheufele, D. A. (2001). Democracy for some? How political talk both informs and polarizes the electorate. In
R. P. Hart \& D. Shaw (Eds.), Communication and U.S. elections: New agendas (pp. 19-32). Lanham, MD: Rowman and Littlefield.

Scruggs, J. F. (1998). "Echo chamber" approach to advocacy. Retrieved from https://www.industry documents.ucsf.edu/docs/ggxn0061

Spohr, D. (2017). Fake news and ideological polarization: Filter bubbles and selective exposure on social media. Business Information Review, 34(3), 150-160.

Stromer-Galley, J., \& Wichowski, A. (2011). Political discussion online. In M. Consalvo \& C. Ess (Eds.), The handbook of Internet studies (pp. 168-187). Malden, MA: Blackwell Publishing Ltd.

Sunstein, C. R. (2002). The law of group polarization. Journal of Political Philosophy, 10(2), 175-195.

Sunstein, C. R. (2008). Republic.com 2.0. Princeton, NJ: Princeton University Press.

Tucker, J., Guess, A., Barbera, P., Vaccari, C., Siegel, A., Sanovich, S., . . . Nyhan, B. (2018). Social media, political polarization, and political disinformation: $A$ review of the scientific literature. Menlo Park, CA: The William and Flora Hewlett Foundation.

Wojcik, S., Messing, S., Smith, A., Rainie, L., \& Hitlin, P. (2018). Bots in the Twittersphere. Washington, DC: Pew Research Center. Retrieved from https://pewrsr. ch/3cNCOye

Wright, S., Graham, T., \& Jackson, D. (2017). Third space and everyday online political talk: Deliberation, polarisation, avoidance. Paper presented at the 67th Annual Conference of the International Communication Association, San Diego, CA. Retrieved from http:// eprints.whiterose.ac.uk/119308

\section{About the Authors}
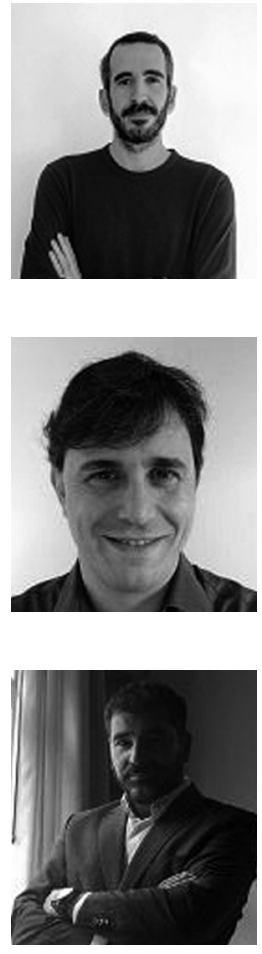

Ignacio-Jesús Serrano-Contreras is a PhD Candidate in Political Science at the University of Granada (Doctoral School of Social Sciences). His research line is focused on feminism and polarization in traditional and social media. He currently works on the development and implementation of algorithms as new methodological methods in order to measure social changes. He has been a visiting researcher at the University of Hildesheim (Germany), the University of Surrey (UK) and the University of Mostar (Bosnia). https://orcid.org/0000-0002-2399-0647

Javier García-Marín is a Professor in the Department of Political Science and Public Administration at the University of Granada. He obtained his PhD in Political Science, and a Master in Economics and International Relations. He has been a Visiting Professor at the London School of Economics and Political Science, the University of Glasgow (Glasgow Media Unit), the Amsterdam School for Communications Research, the Institut d'Études Politiques of Bordeaux and the University of Buenos Aires. He took part in many international projects. http://orcid.org/0000-0002-2766-0266

Óscar G. Luengo is a Professor in the Department of Political Science at the University of Granada. He is Vice-Chair of the Research Committee on Political Communication (RC22) at the International Association of Political Science (IPSA). Director of the Escuela Iberoamericana de Altos Estudios en Gobierno Local of the Unión Iberoamericana de Municipalistas (UIM). He has been a Visiting Researcher at the European University Institute (Florence, Italy), the Johannes Gutenberg-Universität (Mainz, Germany), and the Amsterdam School of Communications Research (The Netherlands). Visiting Professor at University of California, Berkeley (USA) among other universities. http://orcid.org/0000-0001-6597-6459 